\title{
A Semantic Approach to the English Modality
}

\author{
Jinghua Zhang \\ Yanbian University, China
}

\begin{abstract}
Modality is a semantic concept dealing with necessity and possibility of the knowledge of the world. It is basically divided into two types, viz. epistemic modality and deontic modality. Various grammatical categories are possibly used to show modality. However, modal verbs are one of the most important means related to the modality. Modal verbs are flexible in showing modality. This article discusses basic knowledge of modality including definition, classification (epistemic and deontic) and relationship between modality and modal verbs etc.
\end{abstract}

Index Terms—modality, epistemic, deontic, modal verbs, semimodals

\section{INTRODUCTION}

Propositions in the world may be an assertion that concerns truth of the real world based on the factual proposition. However, sometimes it is very hard to assert some proposition based on the background of the knowledge either it is true or not. In order to express this kind of situation, people use the concept modality. Assertion deals with factual propositions based on the real knowledge of the worlds, while modality focuses on the necessities and possibilities of the proposition. Modality is an important semantic category that attracts many scholars' interest. Many expressions in our lives are related to modality. Modality often deals with possibility and necessity. In general, scholars divide modality into two major subcategories, viz., epistemic modality and deontic modality, and modal verbs are the main carriers to show modality. This article will focus on some of the major issues of modality.

Modality is one of the important semantic categories. It refers to "language whose meaning depends on alternate possible worlds" (Portner, 2005, p.154). It is also considered as a category of linguistic meaning having to do with the expression of possibility and necessity. Modality is closely related to the modal auxiliary verbs such as can, must, should etc. to express probability, possibility, necessity, permissibility and obligation etc. Modal verbs with frequent occurrence are will, can, may, must, should, ought to, would, could, might, need ${ }^{1}$, dare, have to ${ }^{2}$, be able to etc. In a word, modality deals with possibility and necessity of the possible world. Though different scholars such as, Saeed (2003) and Kearns (2000) have their own definition to modality, the focus on the possibility and necessity of the language is consistent. Modality is different from assertion which shows definite meaning of a proposition with high level of necessity and it is also different from mood which has similar meanings with modality. The term mood is used by some authors in the same sense as the modality, while most of the scholars argue that modality and mood are the different concepts. They argue that mood is a set of distinctive forms that are used to signal modality, while modality is a facet of illoucutionary force, signaled by grammatical device (viz. moods), to show illocutionary point of the speakers such as commitment to the proposition's believability, obligatoriness, desirability or reality etc. According to Chung and Timberlake (1985), Palmer (1979) and Bybee (1985) et al, modality is expressed by lexical means as well as grammatical means, and it is considered as the synonym of illocutionary force which is related to the knowledge of pragmatics.

However, it is not the case that modality only depends modal verbs. Some other grammatical categories also show modality such as, adverbs, nouns, adjectives and verbs etc. These categories can also show modality. However, modal verbs are generally considered to be the primary source of showing modality.

\section{THEORETICAL BACKGROUND}

Many scholars have made research on modality such as, Jesperson (1924), Von Wright (1951) and Halliday (1985) etc. In this article, perspectives provided by the two famous scholars, viz., Von Wright (1951) and Palmer (1979) are to be concerned. Von Wright (1951) divides modality into four categories. He called modality modes. His classification includes following four categories including two of the most important modalities - epistemic modality and deontic modality.

a. The alethic modes or modes of truth. (Alethic modality)

b. The epistemic modes or modes of knowing. (Epistemic modality)

c. The deontic modes or modes of obligation. (Deontic modality)

d. The existential modes or modes of existence. (Existential modality)

\footnotetext{
${ }^{1}$ Need and dare are more used as main verbs rather than modal verbs.

${ }^{2}$ Some scholars argue that have to, be able to, had better etc. are semimodal verbs. These words are similar in meaning to the typical modal verbs, but they are considered as the supplementary forms to modal verbs.
} 
Each subcategories include a list of concrete contents of modality.

Palmer argues that "There is, perhaps, no area of English grammar that is both more important and more difficult than the system of the modals." (1979, Preface) He defines modality based on the relations between modality and modals, and further remarks that modals and modality has the same relations as form and meaning have. Therefore, they are inseparable.

"Modality in English is defined in terms of the modal auxiliaries, we shall, by including will, have to include within the system of modality both futurity, which seems to belong more to the system of tense, and volition, which has little in common with the more obvious modal concepts of possibility and necessity, but belongs more with the verbs of wanting, hoping, etc. which are essentially lexical rather than grammatical in English. " (Palmer, 1979, p. 2)

From this citation, we can see Palmer's perspectives on modality. He argues that modality deals with possibility and necessity. Modals belong to lexical category and meaning of modality has relations to this lexical category, viz., modal auxiliaries or modal verbs.

In addition, other scholars also defined modality with similar concepts. For example, Saeed (2003) argues that modality is a semantic category "which operates at the sentence level and it is a cover term for devices which allow speakers to express varying degrees of commitment to, or belief in, a proposition". Griffiths (2006) also argues that modality is "the term for a cluster of meanings centered on the notions of necessity and possibility: what must be or what merely might be." (p. 110)

\section{TYPES OF ENGLISH MODALITY}

Modality is generally related to the necessity, possibility, obligation, permissibility, feasibility and certainty etc. As for the classification of modality, there are several proposals. However, many scholars agree that there are generally two major types: epistemic modality and deontic modality. To begin with, let's briefly go over various perspectives on the classification of modality.

Jesperson (1924) divided modality into twenty subcategories which involved "certain attitudes of the mind of the speaker towards the content of the sentence" (1924, p. 313). This kind of classification has a significant influence to the modern research on modality and its classification though it has too many subcategories with many overlapping.

The second classification was made by Rescher (1968, pp24-26). He divided the whole modality system into eight subcategories and his classification also includes two most important categories of modality that we still use nowadays, viz. epistemic modality and deontic modality.

One of the classifications widely accepted by many scholars was made by Von Wright (1951). He divided the modality into four categories. He called modality modes at that time. His classification also included two of the most important items that had been mentioned in the previous two classifications. Von Wright's classification is as follows.

Four modes by Von Wright (1951)

1) The alethic modes or modes of truth.

2) The epistemic modes or modes of knowing.

3) The deontic modes or modes of obligation.

4) The existential modes or modes of existence.

From these classifications, we can see that epistemic modality and deontic modality are the two most important categories in modality, though the criteria of the classification are different.

Based on these classifications, scholars generally divide modality into two major types: epistemic modality and deontic modality.

\section{A. Epistemic Modality}

"Epistemic interpretations have to do with knowledge and understanding" (Griffiths, 2006). It concerns the necessity and possibility of a proposition when there is clear-cut evidence. Therefore, epistemic modality is derived from the fact that can be true from reality. It connotes how much certainty or evidence a speaker has for the proposition expressed by his or her utterance.

(1) There's no answer, Mary must have gone.

Epistemic modality is different from logical modality which always can be true in any case. Epistemic modality is further divided into two subcategories, viz. epistemic necessity and epistemic possibility. Epistemic necessity cannot always be true though it comes from real knowledge of the world. Epistemic possibility, on the contrary, isn't based on the knowledge of the real world. It only provides one of the possibilities according to the speaker's assumption. For example,

(2) Epistemic necessity:

The dinosaurs must have died out suddenly. (Kearns, 2000)

(3) Epistemic possibility:

It is possible that there is intelligent life in deep space. (Kearns, 2000)

Epistemic modality is also divided into evidentiality and judgement modality according to Chung and Timberlake (1985) and Bybee (1985) etc. Evidentiality is an epistemic modality that connotes the speaker's assessment of the evidence for his or her statement. Judgment modality is an epistemic modality that connotes the speaker's strength of 
inference or degree of confidence in the reality of the proposition expressed by his or her utterance. According to Jesperson (1924), epistemic modality is further divided into apodictive, necessitative, assertive, presumptive, dubitative, potential, conditional hypothetical and concessional modality etc. Generally speaking, non-human subjects are used in epistemic sentences.

\section{B. Deontic Modality}

Deontic modality is a modality that connotes the speaker's degree of requirement, desire or commitment to the proposition. It relates to "constraints grounded in society: duty, morality, laws, rules etc." and deontic proposition often concerns obligations or permissions, hope or requirements etc. (Griffiths, 2006) Deontic modality chiefly depends on modal verbs such as, can, must, have to, ought to, could have done etc. to express the meanings. Deontic modality is also divided into deontic necessity and deontic possibility. Deontic necessity concerns obligations and regulations that must be followed by the people, whereas deontic possibility concerns permissible proposition.

(4) Deontic necessity:

You must abide by the rules of the school.

(5) Deontic possibility:

You may go home.

There are also some other ways of classifying deontic modality by the scholars. For example, deontic modality can be divided into commissive modality, directive modality and volitive modality according to Chung and Timberlake (1985) and Palmer (1986). Commissive modality is a deontic modality that connotes the speaker's expressed commitment, as a promise or threat, to bring about the proposition expressed by the utterance. Directive modality is also one of a deontic modality that connotes the speaker's degree of requirement of conformity to the proposition expressed by an utterance. Directive modality is further divided into deliberative mood, imperative mood, jussive mood, obligatory mood, permissive mood, precative mood, prohibitive mood according to Palmer (1986), and Quirk, Greenbaum, Leech, and Svartvik (1985). The third type of deontic modality is volitive modality. It is a deonitc modality that expresses the speaker's attitude of hope, wish, or fear concerning the proposition expressed by the utterance. It is also further divided into imprecative mood and optative mood according to Pei and Gaynor (1954) and Palmer (1986). This kind of classification is very much alike the different categories of the speech acts which are related to the certain illocutionary acts in pragmatics. Jesperson (1924) classifies deontic modality into jussive, compulsive, obligative, advisory, precative, hortative, permissive, promissive, optative (realizable), desiderative (unrealizable) and intentional etc. In general, human subjects are used in deontic sentences.

\section{MODAL VERBS AND MODALity}

Modal verbs are the main carriers of modality. Though we can use inflection of the verbs, viz. mood to show modality, it is not enough. Therefore, it is necessary to apply some other means of modal expressions and that is modal verb. Modal verbs are also regarded as helping verbs or auxiliary verbs.

\section{A. Classification of English Modal Verbs}

Quirk et al. (1985) classify the modal verbs into can/could, may/might, shall/should, will/would, must, be used to, ought to, need and dare etc. Palmer (1986) remarks that modal verbs are can/could, may/might, shall/should, will/would, must, ought, dare and need etc. Modal verbs help the main verb in the sentence to add more information on the different levels of necessity and possibility. Modal verbs that are related to the obligation, requirement or no choice etc. are must, need, have (got) to. Should and ought to are generally related to the recommendation to the hearer. Can and its past form could (without relationship with tense) are connected with possibility. Options, choices and permissions are to be expressed via modal verbs may and might. The following table shows the details.

TABLE I.

CLASSIFICATION OF MODAL VERBS AND SEMANTIC VARIATION

\begin{tabular}{|c|c|c|}
\hline \multicolumn{2}{|c|}{ CLASSIFICATION OF MODAL VERBS AND SEMANTIC VARIATION } \\
\begin{tabular}{|c|c|c|}
\hline Modal verbs & Meanings or illocutionary act & presupposition \\
\hline Must, (have to), will & Obligation, requirement, no choice & Norms \\
\hline Should, ought to & Recommendation & Facts \\
\hline May, might & Options, permissions, choices & Possibility \\
\hline Can & Facts \\
\hline
\end{tabular}
\end{tabular}

\section{B. Modal Verbs and Grade of Possibilities}

Modal verbs have high frequency in practical use. According to the statistics made by Biber et al., "it was found that modals were used in about 15 per cent of clauses that could have them." (1999). Some of the modal verbs used often are will, would, can, could, may, might, shall, should, must and ought to etc. In addition, there are also some other means, (viz., semimodals) to show modality. For instance, have to, need to, be able to etc. In the following parts, some of the basic modals are to be discussed first.

Modal verbs are the basic means or main carriers to show modality. Many of the modal verbs have both epistemic and deontic use of modality. Generally speaking, epistemic modality deals with possibility, necessity, predictability and 
ability etc. Modal verbs like must/ have to, should/ought to, will/shall, would/should, may/might, can/could/be able to etc. are often used for these modality. Deontic modality deals with obligation, volition and permission and modal verbs such as must/have to, will/shall, may/can etc. are often used.

Modal verbs have different grades in their strength of possibilities. For example, must is generally considered as a mark of strong modality. It delivers strong certainty to the proposition by the speaker. In contrast, may, can or might, could are often related to the possibilities with less certainty than must or have to.

Generally speaking, modal verbs are different in showing strength of possibilities. Though most of the modal verbs such as, might, may, could, should, ought to, would, will, must show epistemic possibility, they are different in the strength of possibilities as follows.

TABLE II.

GRADE OF POSSIBILITIES (MODAL VERBS)

\begin{tabular}{|c|c|c|c|}
\hline \multicolumn{2}{|c|}{ Modality } & Modal verbs & Certainty \\
\hline \multirow{10}{*}{$\begin{array}{l}\text { Epistemic } \\
\text { modality }\end{array}$} & Necessity & Must & \multirow[t]{4}{*}{ High certainty } \\
\hline & \multirow{3}{*}{ Predictability } & Will & \\
\hline & & Shall & \\
\hline & & Would & \\
\hline & \multirow{3}{*}{ Probability } & Ought (to) & \\
\hline & & Should & \\
\hline & & Can & \\
\hline & \multirow{3}{*}{ Possibility } & May & \\
\hline & & Could & \multirow{2}{*}{ Uncertainty } \\
\hline & & Might & \\
\hline
\end{tabular}

\section{Modal Verbs and Epistemic Modality}

Epistemic modality concerns the necessity and possibility. Epistemic modality derives from the fact that can be true from reality. Sometimes it connotes certainty or evidence a speaker has for the proposition. Epistemic modality is divided into epistemic necessity and epistemic possibility. Modal verbs can/could; may/might; will/would; shall are often used for epistemic possibility, and must; should/ought to are used for epistemic necessity.

\section{Epistemic Possibility:}

\section{(1) Can/Could:}

Use of can/could is related to the abilities, possibilities (epistemic modality) and permission (deontic modality). Scholars have different perspectives on the classification of can when it is related to the ability. Some scholars argue that can is non-epistemic, while others suggest that can is epistemic. Coates (1983) remarks that can is deontic when it refers to the ability. Coates (1983) regards ability as the core meaning, extending towards possibility as primitive and establish a cline of ability-oriented meanings as one moves towards the periphery. Some scholars also argue that "ability" meaning of can belongs to dynamic modality and it cannot be replaced by may when it refers to the ability.

However, many scholars agree that can is possibly replaced by be able to or be capable of etc. and dynamic modality actually belongs to the epistemic modality (Griffiths, 2006). Therefore, ability meaning of can is considered to be a kind of possibility. When it shows possibilities, can is often used in negative or interrogative sentences. According to the statistics (Lancaster Corpus, cf. Coates, 1983), among three major meanings of can, possibility occupies the highest rate. Could may be used as the past tense of can. However, in many cases, it has no relationship with past tense, but politeness or some other indirect speech which have pragmatic considerations. Could (possibility) is much more related to the remoteness in time and reality.

(6) Can you help me tomorrow? (ability) (Griffiths, 2006)

? May you help me tomorrow?

(7) He can't finish his task. (possibility)

Can you do it for me? (possibility)

(8) Could you give me some help? (politeness)

Could you open the door? (indirect speech)

(9) When John was young, he could read English. (remoteness in time)

If I were you, I could do it in this way. (remoteness in reality)

(2) May/Might:

May/might is related to possibility. However, might has lower strength than may in the degree of possibility. Both may and might are used as epistemic modality to show possibility. Might is often used to show either mere possibility of present situation or politeness. Might is generally weaker than may in the possibility.

(10) He may be home. (possibility)

He might be home. (mere possibility)

Might you be free to help me tomorrow? (politeness) (Griffiths, 2006, p. 111)

I thought that he might come to school. (mere possibility)

(3) Will/Would:

Will and would are often concerned with prediction. Therefore, they are much related to the futurity. Because 
prediction is made by personal judgement on the possibilities, it often shows epistemic modality. Would is often related politeness as well. If it is used as the past tense of will, it means past prediction or past futurity. Will/would also is used as deontic modality.

(11) He will be here at 5. (prediction-futurity)

I will come this afternoon. (prediction-futurity)

Would you help me? (politeness)

I thought he would be here at 5 . (past futurity)

(4) Shall:

Shall can also show prediction as will. However, it is restricted in the use of first person subject. However, in modern English, particularly, in American English, will is used even in the structures with first person subject to show prediction in the future. In the interrogative sentences, shall is used as obligational meaning, viz. deontic modality rather than epistemic modality.

(12) I shall/will be happy if he comes. (prediction)

I shall finish the work if others help me. (prediction)

\section{Epistemic Necessity:}

\section{(1) Must:}

Must often deals with epistemic necessity. In addition, must is also used as deontic modality to show obligation. It is hard to differentiate these two modalities. Therefore, scholars argue that context is very important to distinguish epistemic and deontic modality of must. Must often emphasizes subjectivity rather than objectivity. Have to which has the similar meaning with must can't be replaced by must in showing epistemic modality. Have to is only used as deontic modality.

(13) The ground is wet. It must have rained. (necessity)

(14) He must be studying in the classroom, because he always does so.(epistemic necessity)

He must be studying in the classroom, because he has on other places to go. (deontic)

Negated must is often replaced by can't when it shows epistemic necessity. Must and can are different modals. However, when they are negated, the meaning becomes identical because the two sentences are convertible based on the relative scope relationship.

(15) You must not provide the receipt.

You can't provide the receipt.

You must not provide the receipt. $\Leftrightarrow$ It is necessarily not that you provide the receipt. $\Rightarrow$ necessarily not $\mathrm{P}$

You can't provide the receipt. $\Leftrightarrow$ It is not possible that you provide the receipt. $\Rightarrow$ Not possibly $\mathrm{P}$

necessarily not $\mathrm{P}$ (proposition) $\Leftrightarrow$ not possibly $\mathrm{P}$ (proposition)

You must not provide the receipt. $\Leftrightarrow$ You can't provide the receipt.

\section{(2) Should/Ought to ${ }^{3}$ :}

Should is used as a necessity modal like must. However, it isn't as strong as must. Generally speaking, should and ought to are interchangeable. Palmer (1979) argues that "it is not at all clear that English makes any distinction between should and ought to". However, some scholars insist that there is difference between should and ought to. One of the representatives who suggests that should and ought to are different is Coates (1983). Should and ought to are weaker in force compared with must and the result will not actually be carried out.

(16) They really should be home by now. (necessity)

They really ought to be home by now. (necessity)

\section{Modal Verbs and Deontic Modality}

Deontic modality is concerned with requirement, desire, commitment, obligations, permissions, hope or requirements etc. (Griffiths, 2006) Deontic modality chiefly depends on modal verbs such as must, have to, ought to, may, can, etc. to express the meanings. Deontic modality often shows the meaning of obligation, volition and permission etc.

\section{Deontic Possibility:}

\section{(1) May; Can:}

May and can are often used to show possibility. However, they are also used as deontic modality. In this case, they are more concerned with permission rather than possibility. Can is more informal than may. Therefore, it is more frequently used in the conversation. In contrast, may is used formally. In some cases, can is disallowed to replace may. Past form of may, might is argued to be stronger in the power of permission than may, and it often transfers to requirement.

(17) You may go home. (permission)

May I come in? (permission)

(18) You can go home. (permission)

You can leave now. (permission)

I will wander along to your loo if I may.

\footnotetext{
${ }^{3}$ Some scholars suggest that ought to is a semimodal verb (Fintel, 2006). This article considers it as a modal verb.
} 
*I will wander along to your loo if I can.

You might take off your dirty shoes. (permission $\Rightarrow$ requirement)

\section{Deontic Necessity:}

\section{(1) Must/Have to ${ }^{4}$ :}

When must/have to is used as deontic meanings, it means necessity and obligation. When must refers to the futurity, it becomes deontic rather than epistemic by showing obligations or duty. Compared with must, have to is more objective. Have to is only used for objective obligation.

(19) You must finish all the tasks. (obligation)

You must receive a good supply of both sunshine and moisture to be healthy. (obligation)

(20) You must be in London next week. (obligation)

You must work hard. (subjective obligation)

You have to work hard. (objective obligation)

\section{(2) Will/Shall:}

Will is used as deontic modality when it is related to the volition. Volition includes intention and willingness. This volition is much related to the futurity. Will is often used in the interrogative sentences with second person subject when it shows willingness. Past form would is also possible in this case. However, the willingness will transfer to the slight obligations to the listeners. When the subject is the first person, volitional or intentional shall shows speaker's undertaking to pursue a course of action and may be treated deontically. In questions, shall shows obligational meaning.

(21) My chauffeur will help you. (willingness)

Will/would you like to help me? (willingness $\Rightarrow$ slight obligation)

(22) I shall do it myself. (volition)

(I intend to do it myself.)

(23) Shall we replace the carpets? (obligation)

(Let's replace the carpets.)

\section{(3) Should/Ought (to):}

Should is the past form of shall. Should and ought to are almost the same when they are used as deontic modality. Coates (1983) argues that,

"It is possible that OUGHT occurs more frequently in speech than in written language because of its potentiality for stress. That is, if a speaker wants to emphasize the modality expressed by OUGHT and SHOULD, he will tend to choose OUGHT rather than SHOULD. This distinction is lost, however, in written language". (p. 70)

Both should and ought (to) focus on subjectivity rather than objectivity. Though should and ought to show obligation similar to must, they are not interchangeable. Compared with must/have to, should and ought to are much weaker in showing deontic modality. What's more, the result will not actually be carried out, when should and ought to are used.

(24) * I must finish the work, but I don't want to. (contradictory)

I should/ought to finish the work, but I don't want to. (deontic)

(25) * I had to finish the work, but I didn't. (contradictory)

I should/ought to finish the work, but I didn't. (deontic)

\section{E. Semimodals}

In addition to the modals discussed above, there are some more words which are considered as semimodals. Semimodals have both features of main verbs and modal verbs. Quirk et al. (1972) call these words semi-auxiliaries, Chapin (1973) calls them quasi-modals and Palmer (1974) calls them quasi-auxiliaries. These semimodal verbs are need, be able to, dare and had better etc. Semimodals have the meanings similar to modals. It is reported that there are about twenty semimodal verbs in English (Quirk et al, 1972). Some of the major semimodals commonly concerned are need, be able to, dare, had better, would rather and be going to etc. and these are closely related to the epistemic and deontic modality respectively.

\section{F. Flexibility and Ambiguity of Modal Verbs}

Modal verbs can be used flexibly in showing either epistemic modality or deontic modality. In the following part, the article focuses on some of the core modal verbs used for epistemic modality and deontic modality. As a matter of fact, many of the modal verbs can be used for both epistemic modality and deontic modality. Firstly, we will see must, have to and will. Must is a modal verb with strong possibility derived from the factual proposition. However, it can be related to the obligations as well.

(26) a. He must be a student because he wears school uniform. (Epistemic)

b. He must finish all the work till 5 o'clock PM. (Deontic)

(27) This has to be a joke. (Griffiths, 2006)

a. Epistemic modality: This must be a joke, because nobody believes it. (Possibility)

b. Deontic modality: This must be a joke. Otherwise, the situation will become very serious. (Requirement or hope)

\footnotetext{
${ }^{4}$ Quirk et al. argue that have to is a semi-auxiliary verb.
} 
Sometimes, words like please can be considered as one of the markers to distinguish the epistemic from deontic modality. Because the word please itself shows polite requirement, sentences including please generally belong to deontic modality. When it is used in the epistemic modality, it functions as the converter to change epistemic modality into deontic modality. In the following example (28), the sentence sounds like someone with a vested interest in this proposition praying that its truth will be confirmed or accepted.

(28) Warmer summers must please be a sign of global warming. (Epistemic $\rightarrow$ Deontic) (Griffiths, 2006)

\section{CONCLUSION}

Research on modality is closely related to the possible world. Modality shows necessity and possibility of the world. This article focuses on some major aspects of modality such as, epistemic modality and deontic modality, usage of basic modal verbs, some semimodals that are frequently used and ambiguity of modals in meanings etc.

Modality deals with necessity and possibility. These two are the core concepts of modality. Many scholars classified modality according to their own standard. However, epistemic and deontic modality are the two forms existing in all the classification types. That implies epistemic and deontic modalities are most frequently used. Modal verbs are the main carriers to show modality. This article analyzes major types of modality and semimodal verbs/semi-auxiliaries such as need, dare, be able to etc.

Modality is a very important semantic concept that attracts many scholars' interests. A number of studies on modality have been conducted. In addition to the modal verbs, some other syntactic forms such as adverbs, nouns, verbs, adjectives etc also can represent modality. However, this part is not much concerned in this article. These are also many intriguing topics in the semantic field of modality and further studies will be pursued in the future.

\section{REFERENCES}

[1] Biber, D., et al. (1999). Longman Grammar of Spoken and Written English. London: Pearson Education Limited.

[2] Bybee, J. (1985). Morphology, TSL No.9, Amsterdam: J. Benjamins.

[3] Chapin, P. G. (1973). Quasi-Modals, Journal of Linguistics. Vol.9, No.1, pp1-9.

[4] Chung, Sandrea; and Timberlake, Alan. (1985). "Tense, aspect, and mood". In: Shopen, Timothy(ed.), Language typology and syntactic description. 3. Grammatical categories and the lexicon 202-258. Cambridge etc.: Cambridge University Press.

[5] Coates, J. (1983). The Semantics of the Modal Auxiliaries. London: Croom Helm.

[6] Cruse, Alan. (2000). Meaning in Language. Oxford: Oxford University Press.

[7] Fintel, Kai von. (2006). Modality and Language. In Encyclopedia of Philosophy, $2^{\text {nd }}$ ed. D. M. Borchert: MacMillan.

[8] Givon, Talmy. (2001). Syntax. Volume I. Amsterdam/Philadelphia: John Benjamins Publishing Company.

[9] Griffiths, Patrick. (2006). An Introduction to English Semantics and Pragmatics. Edinburgh: Edinburgh University Press.

[10] Groefsema, Marjolein. (1995). 'Can, may, must and should: a Relevance theoretic account', Journal of Linguistics, Vol.31.No.1,pp53-79.

[11] Halliday, M.A.K. (1985). An Introduction to Functional Grammar. London: Edward Arnold.

[12] Hoye, Leo. (1997). Adverbs and Modality in English. England: Addison Wesley Longman Limited.

[13] Jesperson,O. (1924). The Philosophy of Grammar. NY: Norton.

[14] Kai von Fintel. (2006). Modality and Language, Encyclopedia of Philosophy-Second Edition. Detroit: Millan Reference.

[15] Kearns, Kate. (2000). Semantics. Basingstoke: Macmillan.

[16] Palmer, F.R. (1974). The English Verb. London: Longman.

[17] Palmer, F.R. (1979). Modality and the English Modals. London: Longman.

[18] Palmer, F.R. (1986). Mood and Modality. Cambridge: Cambridge University Press.

[19] Pei, M, Gaynor, F. (1954). Dictionary of Linguistics. New York: Philosophical Library.

[20] Porter, Paul H. (2005). What is Meaning? Fundamentals of Formal Semantics. UK: Blackwell Publishing.

[21] Quirk, R. et al. (1972). A Grammar of Contemporary English. London: Longman.

[22] Quirk R, Greenbaum, S., and Svartvik, J. (1985). A Comprehensive Grammar of the English Language. London: Longman Group Limited.

[23] Rescher, N. (1968). Topics in Philosophical Logic. Dordrecht: Feidel.

[24] Saeed, John I. (2003). Semantics, $2^{\text {nd }}$ ed. Oxford: Blackwell.

[25] Von Wright, G. H. (1951). An Essay in Modal Logic. Amsterdam: North Holland.

Jinghua Zhang, Ph.D. associate professor in English Department of Yanbian University. Her main research interest lies in English linguistics and language education. 